\title{
The effects of National Health Insurance Scheme on equity and quality of diabetes care in secondary healthcare facilities in South- West Nigeria
}

\author{
S. A. Saka ${ }^{1}$ and O. T. Fajemirokun ${ }^{1}$ \\ ${ }^{1}$ Department of Clinical Pharmacy \& Bio-pharmacy, Olabisi Onabanjo University, Sagamu Campus, Ogun State, Nigeria
}

\begin{abstract}
There have been concerns about the influence of the National Health Insurance Scheme (NHIS) on equity and quality of diabetes care in many healthcare settings. This study aimed to assess the effects of NHIS on equity and quality of diabetes care (DC) in Nigeria. A prospective cross-sectional study was carried out among 110 (insured $\mathrm{n}=42$, uninsured=68) consenting type 2-diabetics. Diabetic outpatients on oral hypoglycemic drugs, with at least 4 clinic visits prior to the time of the study were consecutively selected at two NHIS accredited public hospitals in Southwest, Nigeria. Patients' perceptions of equity and quality of DC were assessed using a validated 27 items questionnaire. The medical care and pharmaceutical care in diabetes were independently assessed using medical chart review and a direct observation of dispensing pharmacists' activities respectively. Chi-squared test was used to determine associations between variables. Majority $(61.8 \%)$ of the study participants were uninsured. Females $(50.9 \%)$ were more than the males (49.1\%), 40.0\% had post-secondary qualifications. The mean ages for the insured and uninsured were $52.02 \pm 11.6$ and 58.97 \pm 9.3 years respectively. The insured and the uninsured differ in their perceptions of drug availability $(p<0.001)$. The pharmacists' counselling time $(p<0.001)$ differs between the groups. The quality of medical care provided to the diabetics was generally low. The NHIS did not influence the quality of DC, though it may have engendered inequity in pharmaceutical care in the facilities.

Journal of Medical and Biomedical Sciences (2018) 7(1), 11 - 21
\end{abstract}

Keywords: Health insurance, quality, equity, diabetes care

\section{INTRODUCTION}

National Health Insurance Scheme (NHIS) has been widely accepted by many low-middle income countries (LMICs) with the belief that it will eliminate inequity, and improve healthcare access to the population (Adinma et al., 2010). The aim of the scheme regarding improvement in health care accessibility appears to have been largely achieved in many nations, however, effects of the scheme on equity and quality of healthcare are still being debated (Adekunle, 2011; Stephen and Kehinde, 2013; Abuosi et al., 2016). Perceptions of equity and quality of health care determine patients' satisfaction with health care system, in addition to influencing their decisions to participate in the NHIS (Alhassan

Correspondence: $S A K A, S$. Ajibola, Department of Clinical Pharmacy \& Bio-pharmacy, Olabisi Onabanjo University, Sagamu Campus, Ogun State, Nigeria

Email: sulsak01@yahoo.com; or

ajibola.saka@oouagoiwoye.edu.ng et al., 2015; Amo-Adjei et al., 2016). Equity in healthcare delivery aims at eliminating the disparity in availability and quality of care provided to patients irrespective of their socio-economic standing (Mayberry et al., 2006).

Quality healthcare is defined as the degree of the consistency of healthcare services with the current professional knowledge, and its contribution to the achievement of desired health outcomes (Institute of Medicine, 2006). Major attributes of a quality health care include equitability, prompt, patient-centered, safe, efficient and effective services (Mayberry et al., 2006). These attributes are often measured by both patient perceptions and satisfaction with care, and the evaluation of the technical processes involved in the care delivery (Health System Improvement, 2014).

The technical processes involved in healthcare delivery being structurally and professionally 


\section{Healh insurance and equity of diabetes care} Saka and Fajemirokun

defined practices and protocols are usually not known by patients (Institute of Medicine, 2006). As a result, absolute reliance on patients' perceptions to judge the quality of healthcare may be faulty (Godil et al., 2013).

In addition, patients' perceptions of healthcare quality are often influenced by their socio-economic and cultural orientation and their limited knowledge of what constitutes quality health care (NketiahAmponsah and Hiemenz, 2009; Robyn et al., 2013). In order to holistically assess NHIS for equity and quality of care, and to design effective interventions, the technical aspect of quality should be assessed in addition to the evaluation of the patients' perceptions (Alhassan et al., 2015). Medical chart review and evaluation of administrative data have been consistently used to evaluate the technical aspect of health care delivery because they provide precise information on the quality of disease investigations and treatments to the patients (Adekunle, 2011; HSI, 2014; Amo-Adjei et al., 2016).

Previous studies that evaluated the impact of NHIS on the equity and quality of care from patients' perceptions in sub-Saharan Africa reported that NHIS accredited facilities provided low-quality services to patients (Mohammed et al., 2011; Dalinjong and Laar, 2012; Abuosi et al., 2016; Amo-Adjei et al., 2016). There was, however, no consensus on the effect of the scheme on equity of care between the insured and the uninsured (Adekunle, 2011; Dalinjong and Laar, 2012; Stephen and Kehinde, 2013; Abuosi et al., 2016).

Type-2 diabetes is on the increase in Nigeria and less than $10 \%$ of the estimated 4 million Nigerian diabetics are currently on NHIS (NHIS, 2010). The negative impacts of the disease on patients' quality of life, national productivity and healthcare expenditure in many nations have been well documented (Schofield et al., 2014; Fasanmade and Dagogo-Jack, 2015). It has, however, been shown that with a quality diabetes care, the morbidity and mortality associated with the disease can be reduced (American Diabetes Association, 2015). The essentials of a quality DC include appropriate diagnosis, proper examination of patients, quality prescribing, counselling and education of patients and relatives about the disease, and encouragement of patients on self-monitoring of blood glucose (International Diabetes Federation, 2012; American Diabetes Association, 2015).

In Nigeria, the NHIS commenced operation with the formal sector of the economy in 2005, however, within a decade of its operation, there have been complaints from many insured clients (NHIS, 2010; Mohammed et al., 2013) The extent and nature of the complaints require an in-depth evaluation of the scheme regarding equity and quality of care. This study aimed to assess equity and quality of diabetes care in secondary healthcare facilities (SHFs) in Nigeria.

\section{METHODS}

\section{Study design}

A prospective cross-sectional study was carried out among consecutively selected insured $(n=42)$ and uninsured $(n=68)$ type- 2 diabetics between May and September 2015. A total of 169 outpatient diabetics (uninsured 108; insured 61) were registered in the hospitals during the study period. The validity of patients' NHIS registration was confirmed through the NHIS offices in the hospitals. The sample size of 118 was considered adequate based on sample size calculation using a 5\% margin of error at 95\% confidence level and the available population of 169.

Eligible patients were approached to participate in the study during registration for consultation with physicians after the aims and procedures for the study had been explained to the patients. Patients who gave consent to participate were given consent forms to fill. Consenting type 2 diabetics on oral anti-diabetes drugs (OADs), who had at least four diabetes clinic visits prior to the commencement of the study were included. Patients were excluded if; on insulin because insulin was not covered under the NHIS at the time of the study, transferred to another level of care such as emergency/intensive care, were unable to answer the questionnaire, or based on vision and hearing impairments. This 
study designs, patients' selection procedure, and exclusion have been previously described (Ajibola and Timothy, 2017).

The patients' perceptions of services, equity, quality of medical (MC) and pharmaceutical care (PC) were assessed using a validated researcher-administered questionnaire. Independent assessment of the quality of medical care was carried out using the patients' medical chart review. A direct observation of pharmacists' practice was carried out by a PC expert to assess selected PC services provided to the patients. Ethical approval was obtained from the Olabisi Onabanjo University Teaching Hospital Health Research Ethics Committee (OOUTH/ HREC/3/007) and Ogun State Ministry of Health. Patients also gave written consents.

\section{Study settings}

This study was carried out at Jericho Nursing Home, Ibadan, Oyo State and State Hospital Ijebu-Ode, Ogun State, Nigeria. The hospitals are public secondary healthcare facilities (SHF) situated in the Southwest region of Nigeria. Both cater for the healthcare needs of ambulatory and inpatients. The healthcare workers in the facilities had the privilege of a dedicated training on diabetes care funded by an international donor agency.

\section{Study procedure}

Evaluation of patients' perceptions of hospital services and diabetes care

Quality of hospital services and diabetes care were assessed from the patients' perceptions using a researcher-guided questionnaire. The questionnaire which was developed by the researchers was validated by an academic pharmacist and 2 hospital pharmacists. The questionnaire was initially piloted among 8 diabetics in another secondary healthcare facility in Oyo State. The questionnaire consists of 27 -items which were sectioned into 3 parts. Seven questions evaluated patients' socio-demographics, 8 closed "Yes" or "No" questions were used to assess participants' perceptions of selected quality hospital services and health workers attitude. Twelve questions evaluated participants' perceptions of selected PC services in the healthcare facilities using
Healh insurance and equity of diabetes care Saka and Fajemirokun

a 5-point Likert scale "never to very often." The options were compressed to 3 in the result presentation based on the response received, with the option "never" removed and "very often" and "often" merged and re-coded "always". A total of 120 copies of the questionnaire which took about 10 minutes to complete was administered to the participants while waiting for the consultation with the physicians. The questionnaire that was not returned or not properly filled were excluded from the final analysis. Perceptions of diabetes care between the insured and the uninsured were compared.

\section{Assessment of the medical care}

Medical chart review was carried out to evaluate the quality of medical care. Medical care was assessed based on the qualities of medicine prescribing and patients' assessments by physicians. Medical records of the participants were retrieved immediately after consultation. Information such as patients' socio-demographics, co-morbidities, time of diagnosis, medication use, physicians' documentation of patients' medication adherence, physical assessments of patients and laboratory investigations recommended were extracted from the records.

\section{Evaluation of the pharmaceutical care}

An expert in PC assessed selected PC services through a direct observation of attending pharmacists' dispensing practices and rated pharmacists' performance on each of the services. Pharmaceutical care services in diabetes such as counselling on medication adherence, quality of medication information and documentation of care were evaluated using a 5-point Likert scale ranging from "excellent" to "very poor".

The assessment chart was cross-matched with the identity on the questionnaire. The specialist did not have access to the patients' medical records and had no prior knowledge of the patients' insurance status while the dispensing pharmacists were blinded to the PC services being assessed. The same specialist evaluated the PC in both facilities used in the study. 


\section{Healh insurance and equity of diabetes care}

Saka and Fajemirokun

\section{Statistical analysis}

Data were analysed using Statistical Package for

Social Sciences (SPSS version 20). Data were presented using descriptive statistics such as frequency, percentage and means. Associations between variables were determined using the Chi-squared test.

P-values $<0.05$ were considered significant.

\section{RESULTS}

Selection of the participants

A total of 146 out of 169 patients (86.4\%) diabetic patients were eligible for the study, of which 26 $(17.8 \%)$ were excluded due to: referral to another level of care (7), various impairments (5), and non-consenting (14) leaving only 120 patients who were administered the questionnaire. A response rate of $91.7 \%(110 / 120)$ was achieved with the questionnaire, $6(5.0 \%)$ copies of the questionnaire were not sufficiently filled while $4(3.3 \%)$ were not returned. Only the 110 patients included in the survey were

Table 1: Socio-economic demographics of the respondents

\begin{tabular}{llll}
\hline Variables & $\begin{array}{c}\text { NHIS } \\
\text { n (\%) }\end{array}$ & $\begin{array}{c}\text { Uninsured } \\
\text { n (\%) }\end{array}$ & P-value \\
\hline $\begin{array}{l}\text { Gender } \\
\text { Male }\end{array}$ & $21(38.9)$ & $33(61.1)$ & 0.538 \\
Female & $21(37.5)$ & $35(62.5)$ & \\
Age & & & \\
30-39 years & $2(20.0)$ & $8(80.0)$ & 0.001 \\
40-49 years & $16(66.7)$ & $8(33.3)$ & \\
50-59 years & $19(51.9)$ & $18(48.6)$ & \\
60years and above & $5(12.8)$ & $34(87.2)$ & \\
Marital status & & & \\
Single & $8(28.6)$ & $20(71.4)$ & 0.017 \\
Married & $34(39.0)$ & $48(61.0)$ & \\
Education status & & & \\
No schooling & $5(29.4)$ & $12(70.6)$ & 0.006 \\
Primary & $2(8.7)$ & $21(91.3)$ & \\
Secondary & $11(42.3)$ & $15(57.7)$ & \\
Post-secondary & $24(54.5)$ & $20(45.5)$ & \\
Monthly income & & & \\
Below \#20,000 & $4(17.4)$ & $19(82.6)$ & 0.001 \\
\#20,000-29,000 & $3(11.1)$ & $24(88.9)$ & \\
\#30,000-39,000 & $7(58.3)$ & $5(41.7)$ & \\
\#40,000-49,000 & $7(53.8)$ & $6(46.2)$ & \\
\#50,000 & $21(60.0)$ & $14(40.0)$ & \\
\hline
\end{tabular}

Data presented as number (percentages) *chisquared p-value assessed in the subsequent stages of the study.

\section{Demographics of the participants}

A total of 110 diabetics participated in the study. The majority of the study participants $(68 / 110$; $61.8 \%)$ were uninsured. Females $(56 / 110 ; 50.9 \%)$ were more than the males $(54 / 110 ; 49.1 \%)$, $(44 / 110 ; 40.0 \%)$ had post-secondary qualifications. The mean ages for the insured and uninsured were $52.02 \pm 11.6$ and 58.97 \pm 9.3years respectively $(\mathrm{p}=0.001)($ Table 1).

Table 2: Frequency of Co-morbidities among the Study Participants

\begin{tabular}{lll}
\hline Co-morbidities & Frequency & Percentages \\
\hline Hypertension & 36 & $32.7 \%$ \\
Arthritis & 7 & $6.4 \%$ \\
Peptic ulcer & 3 & $2.7 \%$ \\
Hypertension + Peptic Ulcer & 2 & $1.8 \%$ \\
Hypertension + Arthritis & 5 & $4.5 \%$ \\
Hypertension +Obesity & 1 & $0.9 \%$ \\
Arthritis + Peptic Ulcer & 1 & $0.9 \%$ \\
Hypertension+Hyperlipidaemia & 3 & $2.7 \%$ \\
Asthma + Hypertension & 1 & $0.9 \%$ \\
Diabetes only & 51 & $46.4 \%$ \\
\hline
\end{tabular}

Data presented as frequency and percentages

Hypertension alone (36/110; 32.7\%); Arthritis $(7 / 110 ; 6.4 \%)$ were the most commonly diagnosed co-morbidities among the respondents (Table 2).

Patients' perceptions of the pharmaceutical care services in the facilities

The insured $(30 / 39 ; 76.9 \% ; \quad \mathrm{p}=0.0006)$ claimed drugs were always available. The majority (72/110; $65.5 \% ; \mathrm{p}=0.1497)$ claimed the physicians had never examined their feet (Table 3).

Pharmacists rarely gave advice on non-pharmacological treatment according to the majority of the uninsured $(48 / 66 ; 72.7 \% ; \mathrm{p}=0.004)$ that responded to the question on pharmacists counselling. 101 of 106 (95.3\%) claimed pharmacists provided dosage information always (Table 4).

\section{Medical chart review results}

The majority $(57 / 110 ; 51.8 \%)$ of the patients had been diagnosed with diabetes for more than 5 years, 
Healh insurance and equity of diabetes care

Saka and Fajemirokun

Table 3: Respondents' perceptions of elements of quality service and diabetes care

\begin{tabular}{lcccc}
\hline Services & Yes, $\mathbf{n}(\%)$ & No, $\mathbf{n}(\%)$ & Chi-square & p-values \\
\hline Drug affordability & $41(97.6)$ & $1(2.4)$ & & \\
Insured (n=42) & $61(89.7)$ & $7(10.3$ & 2.4108 & 0.1205 \\
Uninsured (n=68) & & & & \\
Drug availability & $30(76.9)$ & $9(23.1)$ & 11.772 & $<0.001$ \\
Insured (n=39) & $29(42.6)$ & $39(57.4)$ & & \\
Uninsured (n=68) & $37(88.1)$ & $5(11.9)$ & 0.069 & 0.7924 \\
Medicine price stability & $61(89.7)$ & $7(10.3)$ & & \\
Insured (n=42) & $38(92.7)$ & $3(7.3)$ & & \\
Uninsured (n=68) & $16(24.6)$ & $49(75.4)$ & 46.611 & $<0.001$ \\
Doctors' attitude & $41(100.0)$ & $0(0.00)$ & & \\
Insured (n=41) & $63(95.5)$ & $3(4.5)$ & 1.917 & 0.1661 \\
Uninsured (n=65) & & & & \\
Pharmacists attitude & $18(42.9)$ & $24(57.1)$ & 2.0758 & 0.1497 \\
Insured (n=41) & $20(29.4)$ & $48(70.6)$ & & \\
Uninsured (n=66) & & & & \\
Feet examination & $37(92.5)$ & $3(7.5)$ & & \\
Insured (n=42) & $57(87.7)$ & $8(12.3)$ & 0.6103 & 0.4347 \\
Uninsured (n=68) & & & \\
Regular blood check & $21(50.0)$ & $21(50.0)$ & 28.316 & $<0.001$ \\
Insured (n=40) & $63(94.0)$ & $4(6.0)$ & & \\
Uninsured (n=65) & Waiting time & &
\end{tabular}

Chi-square value for analysis of the difference in opinions of the insured and the uninsured. $n=$ number of respondents $(\%)=$ percentages of frequency

$(78 / 110 ; 70.9 \%)$ had more than 4 drugs per prescriptions; and mean drug per prescription was $(5.138 \pm$ 1.565; range: $2-8 ; \mathrm{p}=0.067)$. No record of $\mathrm{HbA}_{1 \mathrm{C}}$ testing and patients' feet examination were documented in any of the patients' records and only 2 $(1.8 \%)$ cases of medication non-adherence based on self-report were documented. The majority (38/39; $97.4 \% ; \mathrm{p}=0.072$ ) of patients aged 60years and above were prescribed glibenclamide. The insured (23/42; $54.8 \% ; \mathrm{p}=0.132)$ were prescribed Lisinopril, the insured $(5 / 7 ; 71.4 \%)$ were prescribed Pioglitazone (Table 5).

\section{Quality and equity of PC services}

Only (101/110; 91.8\%) of participants could be evaluated in the direct observation of the PC services; the remaining insured $(6 / 42 ; 14.3 \%)$, uninsured $(3 / 68 ; 4.4 \%)$ uninsured did not turn-up at the pharmacy. There were significant differences in the quality of information $(\mathrm{p}=0.002)$ and time $(p<0.0005)$ devoted to medication counselling between the insured and the uninsured (Table 6).

\section{DISCUSSION}

\section{Patients' perceptions of hospital services}

Drug availability, affordability and waiting time in a healthcare facility are measures of service quality. In this study, both the insured and the uninsured perceived that drugs were affordable in the healthcare facilities but differed in their perceptions of drug availability, with the uninsured expressing a more negative view. The standard operating procedure for NHIS does not condone drug-stock outs from the service providers (NHIS, 2010). This could have necessitated adequate drug provisions by the providers for the insured, and this may have influenced the insured perceptions of drug availability in the facilities.

Majority of the insured perceived doctors' attitudes 


\section{Healh insurance and equity of diabetes care}

Saka and Fajemirokun

Table 4: Respondents' perceptions of elements of quality service and diabetes care

\begin{tabular}{|c|c|c|c|c|c|}
\hline Pharmaceutical care activities & $\begin{array}{l}\text { Very often and } \\
\text { often, } n(\%)\end{array}$ & Sometimes, $n(\%)$ & Rarely, $\mathrm{n}(\%)$ & $\mathbf{X}^{2}$ & p-values \\
\hline \multicolumn{6}{|c|}{ Willingness to answer patients' questions } \\
\hline Uninsured $(\mathrm{n}=68)$ & $57(83.8)$ & $8(11.8)$ & $3(4.4)$ & 2.11 & 0.349 \\
\hline Insured $(n=42)$ & $38(90.5)$ & $4(9.5)$ & $0(0 \%)$ & & \\
\hline Counselling on medication & & & & &. \\
\hline Uninsured $(n=65)$ & $39(60.0)$ & $21(32.3)$ & $5(7.7)$ & 2.88 & 0.237 \\
\hline Insured $(n=37)$ & $16(43.2)$ & $18(48.7)$ & $3(8.1)$ & & \\
\hline \multicolumn{6}{|l|}{ Adequacy of counselling time } \\
\hline Uninsured $(n=67)$ & $38(56.7)$ & $12(17.9)$ & $17(25.4)$ & 16.51 & $<0.001$ \\
\hline Insured $(n=41)$ & $20(48.8)$ & $20(48.8)$ & $1(2.4)$ & & \\
\hline \multicolumn{6}{|c|}{ Enquiry about adherence to Non-pharm. treatment } \\
\hline Uninsured $(n=66)$ & $6(9.1)$ & $12(18.2)$ & $48(72.7)$ & 11.27 & 0.004 \\
\hline Insured $(n=39)$ & $11(28.2)$ & $12(30.8)$ & $16(41.0)$ & & \\
\hline \multicolumn{6}{|c|}{ Enquiry about the last laboratory investigation } \\
\hline Uninsured $(\mathrm{n}=62)$ & $6(9.7)$ & $7(11.3)$ & $49(79.0)$ & 2.54 & 0.281 \\
\hline Insured $(n=38)$ & $2(5.3)$ & $6(15.8)$ & $30(78.9)$ & & \\
\hline \multicolumn{6}{|c|}{ Education of family members about diabetes } \\
\hline Uninsured $(\mathrm{n}=63)$ & $10(15.9)$ & $14(22.2)$ & $39(61.9)$ & 1.87 & 0.393 \\
\hline Insured $(n=41)$ & $6(14.6)$ & $5(12.2)$ & $30(73.2)$ & & \\
\hline \multicolumn{6}{|c|}{ Explanation of therapeutic goal to the patient } \\
\hline Uninsured $(\mathrm{n}=68)$ & $22(32.4)$ & $10(14.7)$ & $36(52.9)$ & 0.71 & 0.7 \\
\hline Insured $(n=40)$ & $14(35.0)$ & $5(12.5)$ & $21(52.5)$ & & \\
\hline \multicolumn{6}{|c|}{ Emphasis on medication adherence } \\
\hline Uninsured $(\mathrm{n}=67)$ & $56(83.6)$ & $7(10.4)$ & $4(6.0)$ & 0.75 & 0.687 \\
\hline Insured $(n=41)$ & $36(87.8)$ & $4(9.8)$ & $1(2.4)$ & & \\
\hline \multicolumn{6}{|c|}{ Encouragement about self-monitoring of blood glucose } \\
\hline Uninsured $(n=67)$ & $35(52.2)$ & $8(11.9)$ & $24(35.8)$ & 19.77 & $<0.001$ \\
\hline Insured $(n=41)$ & $38(92.7)$ & $2(4.9)$ & $1(2.4)$ & & \\
\hline \multicolumn{6}{|c|}{ Enquiry about patients' experience of OADs } \\
\hline Uninsured $(n=64)$ & $31(48.4)$ & $16(25.0)$ & $17(26.6)$ & 8.39 & 0.015 \\
\hline $\operatorname{Insured}(\mathrm{n}=41)$ & $23(56.1)$ & $16(39.0)$ & $2(4.9)$ & & \\
\hline \multicolumn{6}{|l|}{ Provision of dosage form } \\
\hline Uninsured $(\mathrm{n}=65)$ & $61(93.8)$ & $4(6.2)$ & $0(0.0)$ & 0.77 & 0.68 \\
\hline Insured $(n=41)$ & $40(97.6)$ & $1(2.4)$ & $0(0.0)$ & & \\
\hline
\end{tabular}

Table 5: Pattern of Oral Anti Diabetic Drug Prescription in the Facilities

\begin{tabular}{lcc}
\hline Drugs & Frequency & Percentages \\
\hline Metformin & 1 & 0.9 \\
Metformin + Glibenclamide + methyl dopa & 8 & 7.3 \\
Metformin + Glibenclamide + Lisinopril & 40 & 36.4 \\
Metformin + Glibenclamide+ Omeprazole & 3 & 2.7 \\
Metformin + Glibenclamide + Simvastatin & 2 & 1.8 \\
Metformin + Glibenclamide + Aspirin & 19 & 17.3 \\
Metformin + Pioglitazone & 7 & 6.4 \\
Metformin + Glibenclamide + Nifedipine & 23 & 20.9 \\
Metformin + Glibenclamide + Diuretic & 4 & 3.6 \\
Un documented & 3 & 2.7 \\
\hline
\end{tabular}

Data presented as frequency and percentages 
Healh insurance and equity of diabetes care

Saka and Fajemirokun

Table 6: Comparison of the pharmaceutical care services offered to the insured and the uninsured

\begin{tabular}{|c|c|c|c|c|c|c|c|}
\hline Pharmaceutical care activities & Excellent & Very good & Good & Poor & Very poor & $\mathrm{X}^{2}$ & P-value \\
\hline \multicolumn{8}{|c|}{ Willingness to engage the patient } \\
\hline Uninsured & $18(27.7)$ & $26(40.0)$ & $16(24.6)$ & $2(3.1)$ & $3(4.6)$ & \multirow[t]{2}{*}{2.48} & \multirow[t]{2}{*}{0.648} \\
\hline Insured & $8(22.2)$ & $19(52.8)$ & $8(22.2)$ & $0(0.0)$ & $1(2.8)$ & & \\
\hline \multicolumn{8}{|c|}{ Evaluation of medication adherence } \\
\hline Uninsured & $10(15.4)$ & $15(23.1)$ & $7(10.8)$ & $27(41.5)$ & $6(9.2)$ & \multirow[t]{3}{*}{3.78} & \multirow[t]{3}{*}{0.437} \\
\hline Insured & $7(19.4)$ & 11(30.6) & $4(11.1)$ & $12(33.3)$ & $2(5.6)$ & & \\
\hline \multicolumn{6}{|l|}{ Counseling time } & & \\
\hline Uninsured & $17(26.2)$ & $20(30.8)$ & $28(43.1)$ & $0(0.0)$ & $0(0.0)$ & \multirow[t]{3}{*}{28.82} & \multirow[t]{2}{*}{$<0.001$} \\
\hline Insured & $7(19.4)$ & $16(44.4)$ & $3(8.3)$ & $5(13.9)$ & $5(13.9)$ & & \\
\hline \multicolumn{7}{|l|}{ Quality of information } & \\
\hline Uninsured & $15(23.1)$ & $38(58.5)$ & $12(18.5)$ & $0(0.0)$ & $0(0.0)$ & \multirow[t]{3}{*}{17.54} & \multirow[t]{2}{*}{0.002} \\
\hline Insured & $6(16.7)$ & $12(33.3)$ & $11(30.6)$ & $7(19.4)$ & $0(0.0)$ & & \\
\hline \multicolumn{7}{|l|}{ Documentation of services } & \\
\hline Uninsured & 24(36.9) & $0(0.0)$ & $15(23.1)$ & $20(30.8)$ & $6(9.2)$ & 37.13 & $<0.001$ \\
\hline Insured & $32(88.9)$ & $3(8.3)$ & $1(2.8 \mathrm{~s})$ & $0(0.0)$ & $0(0.0)$ & & \\
\hline
\end{tabular}

Only 101 patients' encounters were evaluated (Uninsured; 65; insured;36). Chi- square value for differences in pharmacists' activity rating observed between the insured and the uninsured

to be professional while the uninsured expressed a different view. It is possible doctors were more cautious of their interactions with the insured, the majority of whom were educated and who might be aware of their rights to quality healthcare services. This study finding agrees with the observations of a similar study in Ghana where the uninsured reportedly perceived more verbal abuse and maltreatment from health workers than the insured (Dalinjong and Laar, 2012).

Quality and equity of medical care

The quality of DC in this study appears to be generally unsatisfactory. Examination of patients' feet for periphery neuropathy is a key component of quality DC (American Diabetes Association, 2015). Diabetes foot ulcer is among the leading causes of diabetes' mortality in Nigeria (Fasanmade and Dagogo-Jack, 2015).

The majority of the patients claimed they never had feet examination despite the fact that many had been diagnosed with diabetes more than 5 years earlier. Their views were also corroborated by the fact that no documentation of such was observed in their medical records. Although there is a wide gap in the ratio of physicians to patients in Nigeria, this, however, does not justify neglecting this vital aspect of DC. The absence of Endocrinologists and
Diabetologists in these facilities could also have contributed to the observation. This study finding contradicts the report of a similar study in Ghana (Abuosi et al., 2016) but supports the findings of earlier reports in Nigeria (NHIS, 2010; Stephen and Kehinde, 2013). There, however, appears to be no discrimination between the insured and the uninsured in this aspect of care, in contradiction to the reports of previous studies in Nigeria and Ghana which indicated that the insured were more likely not to be properly examined by the physicians than the uninsured (Dalinjong and Laar, 2012; Stephen and Kehinde, 2013).

It also appears that none of the diabetic patients had undergone glycated hemoglobin $\left(\mathrm{HbA}_{1 \mathrm{C}}\right)$ testing in the facilities because no documentation of such was recorded in the patients' case notes. This is not, however, uncommon, due to the lack of $\mathrm{HbA}_{1 \mathrm{C}}$ devices in many SHF in the country, and the reluctance of the patients to undergo the test in private health establishments probably due to the fear of cost (Fasanmade and Dagogo-Jack, 2015).

Metformin was the most prescribed OAD for the diabetics in this study. This conforms with the recommendation of standard criteria for DC (International Diabetes Federation, 2012; American Diabetes Association, 2015). The finding is also in 


\section{Healh insurance and equity of diabetes care}

Saka and Fajemirokun

agreement with many previous reports on OADs use among diabetics (Ahmad et al., 2013; Fadare et al., 2015; Sharma et al., 2016). However, the use of pioglitazone in some patients is of concern, especially when no indication for its use was found in the patients' records.

Pioglitazone safety has attracted attention in recent times and with the recent black box warning by the US Food and Drug Administration, its use for diabetes management should be discouraged (Ruiter et al., 2012; Sharma et al., 2016). The fact that pioglitazone was prescribed mostly for the insured also raises a question on the motive behind the prescriptions. Glibenclamide, a long-acting sulphonylurea, was prescribed for almost all the patients above 60 years in this study, against the recommendation of standard criteria for prescribing to the older persons (Gallagher et al., 2008; American Geriatrics Society, 2015). The prolonged hypoglycemic effect of glibenclamide in the older persons reduces patients' quality of life and can contribute to medication non-adherence and poor health outcomes in the patients (Carroll et al., 2011).

The unavailability of cheaper alternatives in the country at the time of the study could possibly have been responsible for this. This prescribing habit, nonetheless, undermines the quality of DC deserved by the patients. Generally, there appears to be no disparity in the treatment provided by the physicians to both the insured and the uninsured diabetics except in the pioglitazone prescription. This observation corroborates the report of Abuosi et al. (2016) that the NHIS did not engender inequity in health care services among the patients.

Patients' adherence to OADs is a great challenge in DC (Ahmad et al., 2013; Fadare et al., 2015). Continuous evaluation of diabetic patients for medication adherence (MA) is part of quality care which determines therapeutic outcomes in diabetes (Carroll et al., 2011). In this study, assessment of MA was rarely documented by the physicians. It is, however, possible that the physicians did not attach much importance to this information. Previous studies in Nigerian healthcare facilities had reported a similar finding (Yusuff and Awotunde, 2005; Stephen and Kehinde, 2013). Documentation of MA can assist the physicians and other healthcare providers to identify patients' specific barriers and to design effective interventions towards improving $\mathrm{MA}$ in the patients.

\section{Equity and quality of pharmaceutical care in diabetes}

Although the majority of the study participants considered the pharmacists as being professional (from the survey), a deeper analysis of the participants' responses to other questions revealed otherwise. Pharmacists according to the majority of the patients rarely enquired about their latest laboratory results, adherence to nonpharmacological treatment and rarely educated their family members about diabetes. These are serious gaps in diabetes management which indicate low-quality service delivery.

The insured more than the uninsured had negative perceptions of the PC services offered in the facilities specifically regarding advice on the nonpharmacological approach to diabetes management, self-monitoring of blood glucose and adequacy of time devoted to counselling. These three aspects are germane to quality DC (American Diabetes Association, 2015).

The perceptions of the insured patients were further corroborated by the finding of the observational study (from PC expert assessment), because many of the insured received less quality information about medications, and less time was devoted to their counselling than their uninsured counterparts. This finding agrees with the observation of similar studies in Ghana and Nigeria which showed that the uninsured patients received more attention from the healthcare providers than the insured (Mohammed et al., 2011; Dalinjong and Laar, 2012; Stephen and Kehinde, 2013). The majority of the insured participants had higher educational qualification than their uninsured counterparts. The observed discrimination in the DC by the pharmacists could, therefore, be a result of the wrong assumption of equivalence of health 
literacy to educational qualification by the pharmacists.

The insured in this study perceived a longer waiting time than the uninsured counterparts. The patients' views were also supported by the finding of the observation of the PC experts in this study which showed that the pharmacists devoted more time to document the insured medication profiles than they did for the uninsured. This is probably, to fulfill the requirement for reimbursement as stipulated in the NHIS protocol. This finding on documentation could possibly have contributed to the perceived longer waiting time experienced by the insured compared to the uninsured in this study.

\section{Limitations of the study}

The study is limited by the number of study sites. The small size of enrolment in this study was due to the small number of diabetics that attended the facilities within the study period and the exclusion criteria adopted. The SHF in Nigeria are less equipped both in materials and human resources (expertise), the DC may not be the same in the tertiary facilities where better-trained health workers are available. Majority of the insured respondents were educated this could have influenced their perceptions of quality of diabetes care. The result of this study should, therefore, be interpreted within the context of these limitations.

\section{CONCLUSIONS}

The finding of this study agrees with the previous reports that NHIS accredited facilities provided low-quality care in many SHFs. Although the MC services appear not discriminatory, inequity was perceived in the PC provision between the insured and the uninsured diabetics in the SHF. The NHIS managers need to focus more attention on the identified areas where inequity seems to exist. Studies on factors that engender inequity and poor quality of care in the NHIS are needed.

\section{COMPETING INTERESTS}

The authors declare that they have no competing interests.
Healh insurance and equity of diabetes care Saka and Fajemirokun

\section{FUNDING}

This research received no funding from any agency in private, public sector or non-governmental.

\section{ACKNOWLEDGMENT}

The authors are grateful to the study participants and the entire staff of the State Hospital Ijebu-Ode and Jericho Nursing Home Ibadan, Nigeria.

\section{AUTHORS' CONTRIBUTIONS}

SSA conceptualized, analysed the data and drafted the manuscript. FTO contributed to the study design and revised the manuscript for intellectual content. SSA and FTO approved the final draft for submission to the journal.

\section{REFERENCES}

Abuosi A.A., Domfeh K.A., Abor J.Y. and Nketiah -Amponsah E. (2016) Health insurance and quality of care: Comparing perceptions of quality between insured and uninsured patients in Ghana's hospitals. International journal for equity in bealth 15(1), 76.

American Diabetes Association. (2015) Standard of medical care in Diabetes. Diabetes Care. . Clin Appl Res Educ 38( sup 1), S1-87.

Adekunle S. (2011) The effects of national health insurance scheme on utilization of health services at Unilorin Teaching Hospital staff clinic, Ilorin, Nigeria. Health Science Journal 5 (2).

Adinma E., Nwakoby B. and Adinma B. (2010) Integrating maternal health services into a health insurance scheme: effect on healthcare delivery. Nigerian quarterly journal of hospital medicine 20(2), 86-93.

American Geriatrics Society. (2015) Updated Beers Criteria for potentially inappropriate medication use in older adults. US department of Health and Human services. Guideline summary ngc:010857

Ahmad N.S., Ramli A., Islahudin F. and Paraidathathu T. (2013) Medication adherence in patients with type 2 diabetes mellitus treated at primary health clinics in Malaysia. Patient preference and adherence 7, 525-530. 


\section{Healh insurance and equity of diabetes care}

Saka and Fajemirokun

Saka S.A. and Fajemirokun T.O. (2017) The Influence of National Health Insurance on Medication Adherence Among Outpatient Type 2 Diabetics in Southwest Nigeria. Journal of Patient Experience 2374373517732384.

Alhassan R.K., Duku S.O., Janssens W., NketiahAmponsah E., Spieker N., van Ostenberg P., Arhinful D.K., Pradhan M. and de Wit T.F.R. (2015) Comparison of perceived and technical healthcare quality in primary health facilities: implications for a sustainable national health insurance scheme in Ghana. PloS one 10(10), e0140109.

Amo-Adjei J., Anku P.J., Amo H.F. and Effah M.O. (2016) Perception of quality of health delivery and health insurance subscription in Ghana. BMC health services research 16(1), 317.

Carroll N.M., Ellis J.L., Luckett C.F. and Raebel M.A. (2011) Improving the validity of determining medication adherence from electronic health record medications orders. Journal of the American Medical Informatics Association $18(5), 717-720$.

Dalinjong P.A. and Laar A.S. (2012) The national health insurance scheme: perceptions and experiences of health care providers and clients in two districts of Ghana. Health economics review 2(1), 13.

Fadare J., Olamoyegun M. and Gbadegesin B. (2015) Medication adherence and direct treatment cost among diabetes patients attending a tertiary healthcare facility in Ogbomosho, Nigeria. Malawi medical journal 27(2), 65-70.

Fasanmade O.A. and Dagogo-Jack S. (2015) Diabetes care in Nigeria. Annals of global health 81 (6), 821-829.

Gallagher P., Ryan C., Byrne S., Kennedy J. and O'Mahony D. (2008) STOPP (Screening Tool of Older Person's Prescriptions) and START (Screening Tool to Alert doctors to Right Treatment). Consensus validation. International journal of clinical pharmacology and therapeutics 46(2), 72-83.

Godil S.S., Parker S.L., Zuckerman S.L., Mendenhall S.K., Devin C.J., Asher A.L. and McGirt M.J. (2013) Determining the quality and effectiveness of surgical spine care: patient satisfaction is not a valid proxy. The Spine Journal 13(9), 1006-1012.

Health System Improvement. (2014) Measuring health care quality: An overview of quality measures1-15. Available at $\mathrm{htt} \mathrm{p}: / /$ familiesusa.org/sites/default/files / product_documents/HSI $\% 20$ Quality $\%$ 20Measurement_Brief_final_web.pdf. Accessed on 30th October 2016.

International Diabetes Federation. (2012) Clinical guidelines Task Force- Global guideline for Type 2 diabetes. Available at https:// www.idf.org/sites/default/files/IDF\% 20T2DM\%20Guideline.pdf. Downloaded on 11th September 2016.

Institute of Medicine (2006) Crossing the quality chasm: The IOM Health Care Quality Initiative. Washington, DC: National Academies Press.

Mayberry R.M., Nicewander D.A., Qin H. and Ballard D.J. (2006) Improving quality and reducing inequities: a challenge in achieving best care. Baylor University Medical Center Proceedings 19, 103-118.

Mohammed S., Bermejo J.L., Souares A., Sauerborn R. and Dong H. (2013) Assessing responsiveness of health care services within a health insurance scheme in Nigeria: users' perspectives. BMC bealth services research 13 (1), 502.

Mohammed S., Sambo M.N. and Dong H. (2011) Understanding client satisfaction with a health insurance scheme in Nigeria: factors and enrollees experiences. Health Research Policy and Systems 9(1), 20.

NHIS (2010) National Health Insurance scheme . [Online]. Available from: http:// www.nhis.gov.ng/. Accessed 27th July, 2016.

Nketiah-Amponsah E. and Hiemenz U. (2009) Determinants of consumer satisfaction of health care in Ghana: does choice of health care provider matter? Global journal of health science 1(2), 50.

Robyn P.J., Bärnighausen T., Souares A., Savadogo G., Bicaba B., Sié A. and Sauerborn R. (2013) Does enrollment status in commu- 
nity-based insurance lead to poorer quality of care? Evidence from Burkina Faso. International journal for equity in health 12(1), 31.

Ruiter R., Visser L.E., van Herk-Sukel M.P., Geelhoed-Duijvestijn P.H., de Bie S., Straus S.M., Mol P.G., Romio S.A., Herings R.M. and Stricker B.H.C. (2012) Prescribing of rosiglitazone and pioglitazone following safety signals. Drug safety 35(6), 471-480.

Schofield D., Cunich M.M., Shrestha R.N., Passey M.E., Veerman L., Callander E.J., Kelly S.J. and Tanton R. (2014) The economic impact of diabetes through lost labour force participation on individuals and government: evidence from a microsimulation model. $B M C$ public health 14(1), 220.

Sharma S., Tandon V.R. and Roshi A.M. (2016) Prescribing pattern of oral antihyperglycaemic
Healh insurance and equity of diabetes care Saka and Fajemirokun

drugs, rationality and adherence to American Diabetes Association (ADA) treatment guidelines among type 2 diabetes mellitus (T2DM) postmenopausal women. Journal of clinical and diagnostic research: JCDR 10(1), OC11.

Stephen O. and Kehinde O. (2013) Equity of care: A comparison of National Health Insurance Scheme enrolees and fee-paying patients at a private health facility in Ibadan, Nigeria. Journal of Public Health and Epidemiology 5(2), 51-55.

Yusuff K. and Awotunde M. (2005) The frequency of drug history documentation in an institutionalized tertiary care setting in Nigeria. J Pharm Pharm Sci 8(2), 140-145.
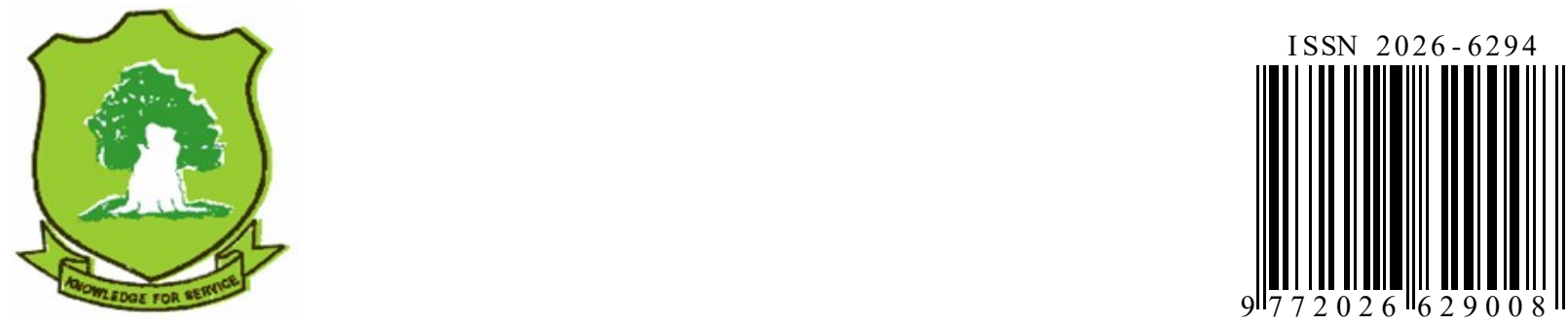